\title{
PENERAPAN PEMBELAJARAN BERBASIS STEM (SCIENCE, TECHNOLOGY, ENGINEERING AND MATHEMATICS) UNTUK MENINGKATKAN KEMAMPUAN CONTROL OF VARIABLE SISWA SMP PADA HUKUM PASCAL
}

\author{
Dessy Agustina $^{1, \text { a) }}$, Ida Kaniawati ${ }^{1}$, Irma Rahma Suwarma ${ }^{1}$ \\ ${ }^{1}$ Prodi Pendidikan Fisika FMIPA UPI, Jl. Dr. Setiabudhi No. 229 Isola, Sukasari, Kota Bandung 40154.
}

Email: a) dessy.agustinaaa8@gmail.com

\begin{abstract}
Abstrak
Kemampuan control of variabel merupakan salah satu kemampuan scientific reasoning yaitu kemampuan yang dimiliki siswa untuk mengontrol variabel. Kemampuan ini sangat diperlukan selama proses penyelidikan ilmiah. Hal ini dikarenakan selama proses penyelidikan melibatkan banyak variabel dan mengontrol variabel untuk menganalisis hubungan antara variabel. Tujuan penelitian ini untuk mengembangkan kemampuan control of variable siswa dengan menerapkan pembelajaran berbasis STEM. Penelitian ini menggunakan metode quasi eksperimen dengan one group pre test and post test desain pada sampel sebanyak 37 siswa menggunakan teknik convience sampling di salah satu sekolah kabupaten Bandung Barat. Pengukuran dilakukan dengan menggunakan tes scientific reasoning berbentuk pilihan ganda bertingkat yang diadopsi dari Lawson Classroom Test Scientific Reasoning (LCTSR). Hasil penelitian menunjukkan peningkatan control of variable siswa setelah diterapkan pembelajaran berbasis STEM memiliki n-gain sebesar 0,45 dalam katagori sedang.
\end{abstract}

Kata-kata kunci: Pembelajaran berbasis STEM, scientific reasoning, control of variable.

\begin{abstract}
The ability of control of variable is one of ability of scientific reasoning that is ability owned by student to control variable. This capability is indispensable during the process of scientific inquiry. This is because during the investigation process involves many variables and control variables to analyze the relationship between variables. The purpose of this research is to develop students control of variable ability by applying STEM-based learning. This study uses quasi experimental method with one group pre test and post test design on samples of 37 students using convience sampling technique in one school district of West Bandung. Measurements were made using a multilayer multiple-dimensional, multiple-choice scientifically adopted test adopted from the Lawson Classroom Test Scientific Reasoning (LCTSR). The result of the research showed that the improvement of control of student variable after applied STEM based learning had n-gain of 0.45 in moderate category.
\end{abstract}

Keywords: STEM-based learning, scientific reasoning, control of variables. 


\section{PENDAHULUAN}

Kemampuan penalaran siswa sangat diperlukan siswa baik dalam pembelajaran fisika maupun dalam kehidupan sehari-hari (Ernawati, 2013)[3][1]. Penalaran ilmiah atau scientific reasoning mempunyai peran penting dalam proses pemecahan masalah (Khan \& Ullah, 2010)[10]. Scientific reasoning meliputi penalaran dan keterampilan pemecahan masalah yang terlibat dalam menghasilkan, menguji, dan memperbaiki hipotesis atau teori, dan dalam hal kemampuan yang dikembangkan sepenuhnya, menggambarkan proses perolehan pengetahuan dan perubahan pengetahuan yang dihasilkan dari kegiatan penyelidikan (Morris et all, 2012)[2]. Ketika siswa memiliki kemampuan scientific reasoning maka siswa tersebut dapat memecahkan masalah yang dihadapinya terutama dalam belajar fisika.

Penyelidikan ilmiah diperlukan dalam pemecahan masalah, dalam penyelidikan ilmiah kemampuan untuk menangani dan mengontrol variabel sangat penting (Tairab, 2016)[4]. Kemampuan mengontrol variabel ini disebut dengan kemampuan control of variable. Control of variable merupakan salah satu dimensi scientific reasoning yang paling penting (Han, 2013)[5].

Pada nyatanya, kemampuan control of variabel siswa masih sangat kurang. Hal tersebut terlihat pada hasil studi pendahuluan ke salah satu sekolah SMP Negeri di Kabupaten Bandung. Dari hasil studi pendahuluan yang dilakukan kepada sejumlah siswa kelas 8 menggunakan tes scientific reasoning siswa yang diadopsi dari Lawson berbentuk pilihan ganda dua tingkat, menunjukkan bahwa kemampuan control of variabel siswa hanya 20,59\%.

Berdasarkan hal tersebut, artikel ini membahas tentang pengembangan kemampuan control of variable dengan menerapkan pembelajaran berbasis STEM. Salah satu proses dalam pembelajaran berbasis STEM yaitu merencanakan dan melakukan investigasi/Penyelidikan (Bybee, 2011)[8]. Pada tahap tersebut siswa melakukan penyelidikan ilmiah dan penyelidikan engineering. Selama proses penyelidikan ilmiah dan penyelidikan engineering siswa akan melibatkan banyak variabel dan kemudian siswa harus mampu mengotrol variabel untuk mengidentifikas variabel. Hal tersebut menunjukkan bahwa pembelajaran berbasis STEM dapat melatihkan dan meningkatkan kemapuan control of variabel siswa. Pada penelitian ini, materi yang diambil yaitu prinsip Hukum Pascal yang bertujuan untuk meningkatkan kemampuan control of variable siswa.

\section{METODE PENELITIAN}

Pada penelitian ini, metode yang digunakan adalah quasi eksperimen dengan one group pre test and post test desain. Penelitian ini dengan menggunakan satu kelas pre-test post-test group desain [7]. sampel penelitian akan diberi treatment yaitu berupa implementasi pembelajaran berbasis STEM. Sebelum diberi treatment, sampel akan diberi tes awal (pretest), kemudian dilanjutkan dengan memberikan treatment, dan terakhir diberikan tes akhir (posttest). Data yang diperoleh berupa skor pretest dan posttest diolah menggunakan gain yang dinormalisasi $\langle g\rangle$ untuk menggambarkan nilai peningkatan posttest terhadap pretest [7].

\section{HASIL DAN PEMBAHASAN}

Hasil dari analisis data yang diperoleh dapat dilihat dari peningkatan control of variabel siswa dengan membandingkan nilai posttest dan pretest. Berikut adalah hasil nilai rata-rata peningkatan scientific reasoning siswa di bawah ini. 


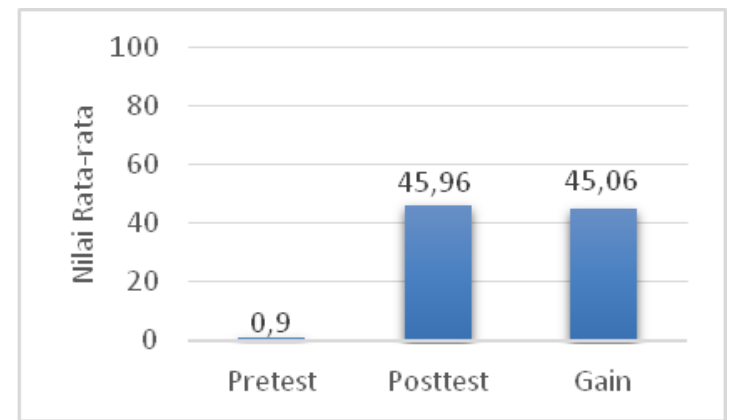

Gambar 1. Nilai Rata-rata Pre-test, Post-test dan Gain

Dari data tersebut terlihat bahwa terdapat peningkatan antara pretest dan posttest dengan nilai rata-rata sebesar 45,06. Lebih jelasnya diperoleh hasil peningkatan control of variabel siswa dengan nilai gain yang telah dinormalisasi sebagai berikut.

Tabel 1. Peningkatan Kemampuan Control of Variable

\begin{tabular}{|c|c|c|}
\hline & Pre-test & Post-test \\
\hline $\mathbf{N}$ & 37 & 37 \\
\hline Mean & 0,03 & 1,38 \\
\hline N-Gain & & \\
\hline
\end{tabular}

Berdasarkan tabel di atas control of variable mengalami peningkatan dengan nilai gain yang dinormalisai sebesar 0,45 berada dalam kategori sedang. Hal tersebut menunjukkan bahwa implementasi pembelajaran berbasis STEM dapat meningkatkan dimensi control of variable. Control of variable dapat dilatihkan melalui proses penyelidikan ilmiah (Han, 2013)[5]. Penyelidikan ilmiah merupakan salah satu komponen dalam pembelajaran STEM (Bybee, 2011)[8]. Kelebihan dari pembelajaran STEM yaitu adanya proses engineering (Torlakson, 2014)[9]. Oleh karena itu dalam pembelajaran STEM selain siswa melakukan penyelidikan ilmiah, siswa juga melakukan penyelidikan engineering. Seperti ilmuan, engineers harus mengidentifikasi variabel yang relevan, memutuskan bagaimana mereka akan mengukur, dan mengumpulkan data untuk dianalisis (Bybee, 2011)[8].

Dari data pada Tabel 2 menunjukkan bahwa kemampuan control of variabel siswa sudah cukup baik, hanya saja masih kurang memuaskan. Control of variable merupakan kemampuan mengontrol variabel untuk menganalisis hubungan antara variabel (Han, 2013)[5]. Hal tersebut terlihat dalam proses penyelidikan ilmiah, dimensi control of variable dilatihkan pada saat siswa menentukan variabel terikat, variabel bebas dan variabel kontrol saat merancang dan melakukan percobaan. Pada tahap tersebut masih ada beberapa siswa yang tidak mengetahui variabel terikat, variabel bebas, dan variabel kontrol.

Selain daripada itu terlihat pada proses penyelidikan engineering, kemampuaan control of variable dilatihkan pada saat siswa mendesain yaitu menentukan ukuran pengisap besar dan pengisap kecil agar mobil dapat terangkat dengan mudah. Agar mobil terangkat dengan mudah ukuran luas penampang pengisap besar lebih besar daripada ukuran luas penampang pengisap kecil. Dari hasil desain setiap kelompok masih banyak yang tidak bisa menentukan ukuran luas penampang pengisap kecil dan ukuran pengisap besar. Hal ini dapat dilihat dari hasil desain setiap kelompok di bawah ini. 


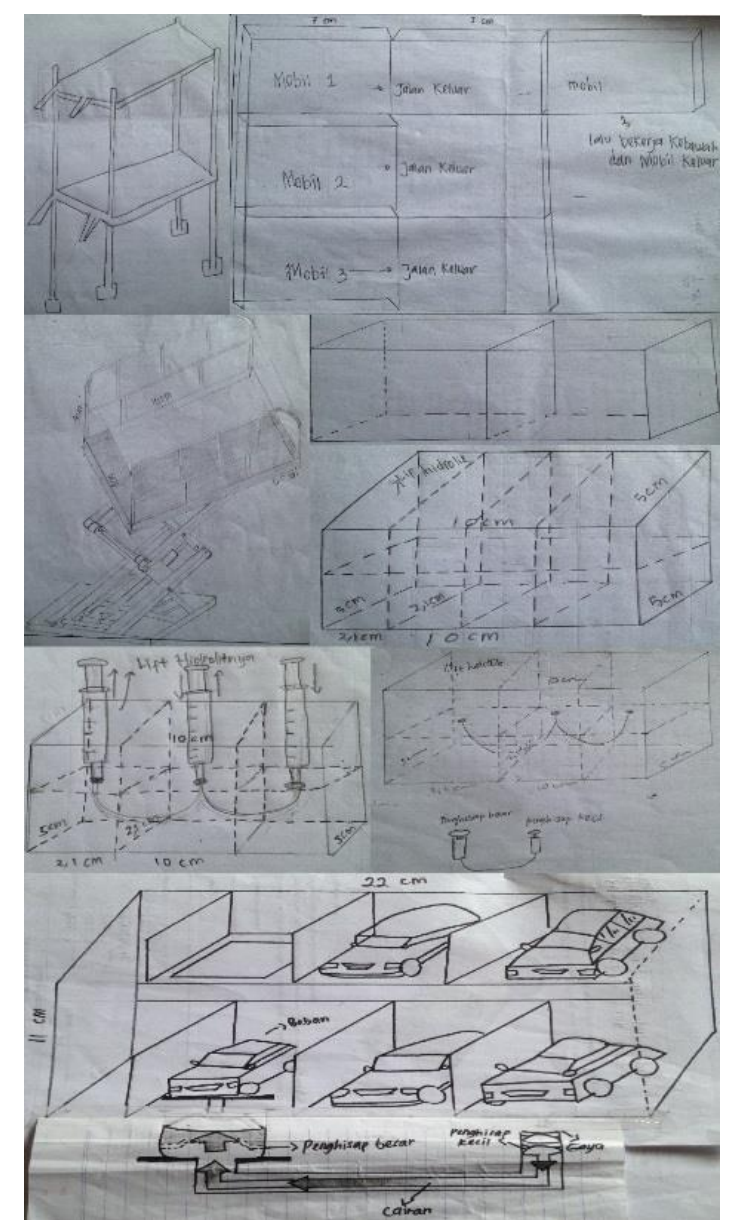

Gambar 2. Hasil Desain Parkiran Hidrolik Setiap Kelompok

Dari Gambar 2 di atas terlihat bahwa siswa tidak menggambarkan pengisap besar dan pengisap kecil dalam desain yang mereka buat, hanya 2 kelompok dari 8 kelompok yang menentukan pengisap besar dan pengisap kecil yang benar. Dari hasil desain terlihat bahwa siswa kurang dalam mengontrol variabel.

\section{SIMPULAN}

Peningkatan kemampuan control of variabel siswa setelah diterapkan pembelajaran STEM diperoleh gain yang dinormalisasi sebesar 0.45 yang berada dalam kategori sedang. Hal tersebut menunjukkan bahwa penerapan pembelajaran berbasis STEM dapat meningkatkan kemampuan control of variabel siswa.

\section{UCAPAN TERIMAKASIH}

Penulis mengucapkan terimakasih kepada Dr. Ida Kaniawati, M.Si. dan Irma Rahma Suwarma, M.Si., Ph.D atas bimbingannya hingga penelitian selesai dilaksanakan. Penulis juga mengucapkan terima kasih kepada Ibu Ela Maelasari, S.Pd. selaku guru SMP Negeri Lembang, siswa kelas VIII, serta Adib Rifqi Setiawan, S.Pd. atas bantuannya selama penelitian berlangsung. 


\section{REFERENSI}

[1] A. R. Setiawan, "Mengonstruksi Rancangan Soal Domain Kompetensi Literasi Saintifik Siswa SMP Kelas VIII pada Topik Gerak Lurus," Wahana Pendidikan Fisika, vol. 2, no. 2, pp. 44-48, 2017.

[2] B. J. Morris et al., “The Emergence of Scientific Reasoning,” Intech, 2012.

[3] Ernawati et al., "Penerapan Model Pembelajaran Learning Cycle untuk Meningkatkan Kemampuan Penalaran Siswa,” 1(2), 2013.

[4] H. H. Tairab, "Assessing Students' Understanding of Control of Variables across Three Grade Levels and Gender," Canadian Center of Science and Education. vol. 9, no. 1, 2016.

[5] J. Han, Scientific Reasoning: Research, Development, and Assessment, The Degree Doctor of Philosophy in the Graduate School of The Ohio State University, 2013.

[6] J. R. Fraenkel \& N. E.Wallen, How to Design and Evaluate Research in Education (7th ed.). New York. McGraw-Hill Companies, 2009.

[7] J. W. Creswell, Research design : qualitative, quantitative, and mixed methods approaches (4th ed.). Thousand Oaks: SAGE Publications, Inc, 2014.

[8] R. W. Bybee, Scientific and Engineering Practices in K-12 Classrooms: Understanding A Framework for K-12 Science Education, NSTA press; Arlington, Virginia, 2011.

[9] T. Torlakson, INNOVATE: ABlueprint for Science, Technology, Engineering, and Mathematics in California Public Education. California. California Departement Of Education, 2014.

[10] W. Khan \& H. Ullah, "Scientific Reasoning: A Solution to the Problem of Induction," Internasional Journal of Basic \& Applied Sciences IJBAS-IJENS, vol.10, no.03, June, 2010. 
